\title{
Fibrinogen Level Predicts Prognosis of Patients with Acute Ischemic Stroke or TIA
}

\author{
Huiqing Hou \\ Beijing Tiantan Hospital https://orcid.org/0000-0003-0226-968X \\ Xianglong Xiang \\ Beijing Tiantan Hospital \\ Yuesong Pan \\ Beijing Tiantan Hospital \\ Hao Li \\ Beijing Tiantan Hospital \\ Xia Meng \\ Beijing Tiantan Hospital \\ Yongjun Wang ( $\square$ yongjunwang@ncrend.org.cn ) \\ Beijing Tiantan Hospital https://orcid.org/0000-0002-9976-2341
}

\section{Research}

Keywords: Fibrinogen, Prognosis, Risk factor, Stroke, Transient ischemic attack

Posted Date: August 28th, 2020

DOI: https://doi.org/10.21203/rs.3.rs-64098/v1

License: (c) (i) This work is licensed under a Creative Commons Attribution 4.0 International License. Read Full License 


\section{Abstract}

Background: Fibrinogen is involved in acute stroke. This study aimed to investigate the association between fibrinogen and prognosis in patients with acute ischemic stroke or transient ischemic attack (TIA).

Methods: Using data from the CNSR- $\triangle$ (Third China National Stroke Registry), this sub-study included 10518 (69\%) consecutive patients who had fibrinogen levels measured. The primary outcome was a poor functional outcome defined as modified Rankin Scale score of 3 to 6 within 90 days. The secondary outcomes were stroke recurrence, ischemic stroke recurrence, composite vascular events, and poor functional outcome during the 1-year follow-up and a new vascular event at 90 days. Multivariate logistic regression and Cox regression analyses were used to assess the associations between fibrinogen and prognosis of patients.

Results: In total, 1446 (13.9\%) patients had a poor functional outcome at 90 days. High fibrinogen levels were associated with poor functional outcome (adjusted odds ratio [OR], 1.35; 95\% confidence interval [CI], 1.12-1.64) at 90 days after adjustment for confounding risk factors. High fibrinogen levels also independently predicted poor functional outcome during the 1-year follow-up. Stroke recurrence occurred in 657 (6.3\%) patients at 90 days. High fibrinogen levels were associated with stroke recurrence, ischemic stroke recurrence, and composite vascular events in the crude model, but further adjustment eliminated these associations in the multivariate models.

Conclusion: Our study showed that high fibrinogen level was independently associated with poor functional outcome but not with stroke recurrence in patients with acute ischemic stroke or TIA.

\section{Background}

Acute ischemic stroke and transient ischemic attack (TIA) occur frequently and are major causes of functional disability. Moreover, stroke recurrence within the 90 -day follow-up period accounts for $10-15 \%$ of these patients [1, 2]. Thus, identifying potential markers associated with prognosis of stroke in addition to traditional risk factors and further developing targeted therapeutics are critical.

Fibrinogen is a pleiotropic protein secreted from the liver that plays critical roles in coagulation, the proinflammatory cascade and the inhibition of tissue repair [3]. Growing data indicate fibrinogen mediates cardiovascular risk through coagulation and inflammatory cascades, which may promote formation of thrombin substrates, platelet aggregation, endothelial activation, and smooth muscle cell proliferation and migration [3, 4]. Several large trails suggested that high fibrinogen level is a risk factor for initial stroke or vascular disease in the general population during long term follow-up period [5-7]. A higher fibrinogen level has been previously observed in patients with acute ischemic stroke [8, 9]. However, the association between fibrinogen and stroke recurrence or a new vascular event is still undefined [10-12]. On the contrary, although the association of high fibrinogen level with death after stroke has been previously expounded [13-15], only a few studies investigated the association between fibrinogen and functional outcome [16-18]. In addition, its predictive value for poor functional outcome after acute stroke is limited and inconsistent $[16,17]$.

The CNSR- $\otimes$ (Third China National Stroke Registry) is a nationwide, multicenter, prospective registry of patients with acute ischemic stroke or TIA [19]. In this subgroup study, we aimed to evaluate the association of fibrinogen levels with poor functional outcome and stroke recurrence.

\section{Methods \\ Study Population}

The CNSR- $\square$ study is a nationwide, consecutive, multicenter, prospective stroke registry that enrolled 15166 patients with acute ischemic stroke or TIA within 7 days of onset who were treated at 201 hospitals in China from August 2015 to March 2018. Acute ischemic stroke was diagnosed according to the WHO criteria [20] and confirmed by brain computed tomography or magnetic resonance imaging. A subset of 10518 patients in the CNSR- $\varangle$ study provided blood samples for the measurement of fibrinogen levels. All participating centers used consistent diagnostic criteria and a standard protocol.

\section{Standard protocol approval, registration, and patient consent}

The study protocol was approved by the Central Institutional Review Board at the Beijing TianTan Hospital. All participants or their legal proxies provided written informed consent.

\section{Biochemical Measurements}


EDTA treated plasma and serum samples were obtained from the CNSR- $\nabla$ patients at the time of enrollment and stored at $-80^{\circ} \mathrm{C}$. No freeze thaw cycles occurred before testing. The fibrinogen, D-dimer and high-sensitive C-reactive protein (hsCRP) levels were measured (from February 2018 to February 2019) in a center laboratory certified by the College of American Pathologists, and the laboratory personnel were blinded to the clinical data. The plasma fibrinogen and D-dimer levels were analyzed with an OLYMPUS AU2700 analyzer (Beckman, Japan) using an immunoturbidimetric assay (Kamiya Biomedical, Seattle, USA) [21-23], which is a mass-based assay with international standards. The serum hsCRP levels were measured with a Cobas c501 analyzer using a cardiac high-sensitive C-reactive protein (latex) assay (Roche, Basel, Switzerland). All measurements were performed according to the manufacturers' instructions.

\section{Patient Follow-up and Outcome Assessment}

The patients were interviewed face to face at 90 days and contacted by telephone at 1 year after enrollment by a trained research coordinator in

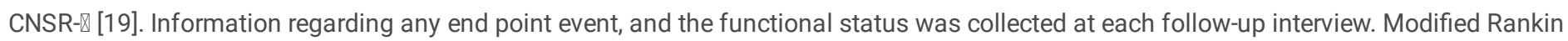
Scale (mRS) scores ranging from 0 to 6 points were used to assess patients' functional dependence.

The primary outcome was poor functional outcome as defined by an mRS score of 3 to 6 at 90 days [24]. The secondary outcomes were stroke recurrence defined as aggravated primary neurological deficit, a new neurological deficit, rehospitalization with a diagnosis of ischemic or hemorrhagic stroke (intracerebral hemorrhage and subarachnoid hemorrhage), ischemic stroke recurrence, composite vascular events (ischemic stroke, hemorrhagic stroke, myocardial infarction, or vascular death), and poor functional outcome during the 1-year follow-up and a new vascular event at 90 days $[24,25]$.

\section{Statistical Analysis}

The baseline characteristics were compared based on the quartiles of the fibrinogen levels using the $\chi^{2}$ test for the categorical variables and Kruskal-Wallis test for the continuous variables. The fibrinogen levels were examined continuously and as quartiles to investigate their association with the prognosis of ischemic stroke or TIA. The association between the fibrinogen levels and poor functional outcome was estimated using logistic regression models, while the association between the fibrinogen levels and a new vascular event was estimated using Cox proportional hazards models. The potential confounders included demographic factors, prior published clinical risk factors, stroke subtypes, complications during hospitalization, and medications used during hospitalization. All significant covariates with a $P$ value $<0.05$ in the univariate analysis were included to the multivariate model. We also evaluated the association between the fibrinogen level and the risk of poor functional outcome using a logistic regression model with restricted cubic splines for fibrinogen levels (continuous measures) that was adjusted for all potential covariates. The 5 knots of the spline were placed at the 5 th, 25 th, 50th, 75 th, and 95 th percentiles of the fibrinogen levels, and the first quartile of the fibrinogen level was treated as the reference.

All statistical analyses were performed with SAS software, version 9.4 (SAS Institute Inc., Cary, NC). All $P$ values were 2-sided, and $P<0.05$ was considered indicative of statistical significance.

\section{Results}

\section{Patient Characteristics}

In total, 15166 patients with acute ischemic stroke or TIA were enrolled in the CNSR- $\nabla$ study. Among these patients, 4648 patients who did not provide blood samples were excluded. A subset of 10518 patients constituted the study population for this analysis (Fig. 1).

The baseline characteristics of the 10518 patients stratified according to the fibrinogen quartiles are shown in Table 1 . The mean age was 62.3 \pm 11.4 years, and 3283 (31.21\%) patients were female. The median fibrinogen level was 378.0 (interquartile range [IQR], 315.0-451.5) mg/dl. The patients with higher fibrinogen levels were significantly older, more likely to be female, had a higher baseline National Institutes of Health Stroke Scale (NIHSS) score, and had a history of hypertension, diabetes mellitus, atrial fibrillation, and ischemic stroke (Table 1). 
Table 1

Characteristics of the study population $(n=10518)$ by fibrinogen quartiles

\begin{tabular}{|c|c|c|c|c|c|c|}
\hline \multirow[t]{2}{*}{ Characteristics } & \multirow[t]{2}{*}{ All (N= 10 518) } & \multicolumn{4}{|c|}{ Quartiles of fibrinogen } & \multirow{2}{*}{$\begin{array}{l}P \\
\text { Value }\end{array}$} \\
\hline & & Q1 (N = 2592) & Q2 (N = 2576) & Q3 (N = 2697) & Q4 (N = 2653)* & \\
\hline Age, mean (SD), y & $62.3 \pm 11.4$ & $59.8 \pm 11.3$ & $61.5 \pm 11.5$ & $63.3 \pm 11.1$ & $64.4 \pm 11.0$ & $<.001$ \\
\hline Female, n (\%) & 3283 (31.2) & $637(24.6)$ & $747(29.0)$ & $890(33.0)$ & 1009 (38.0) & $<.001$ \\
\hline BMI, median (IQR) & $\begin{array}{l}24.5(22.5- \\
26.5)\end{array}$ & $\begin{array}{l}24.5(22.5- \\
26.4)\end{array}$ & $\begin{array}{l}24.4(22.5- \\
26.4)\end{array}$ & $\begin{array}{l}24.4(22.5- \\
26.5)\end{array}$ & $\begin{array}{l}24.5(22.6- \\
26.7)\end{array}$ & 0.172 \\
\hline \multicolumn{7}{|l|}{ Medical history, n (\%) } \\
\hline Hypertension & $6573(62.5)$ & $1536(59.3)$ & $1568(60.9)$ & $1670(61.9)$ & $1799(67.8)$ & $<.001$ \\
\hline Diabetes mellitus & $2486(23.6)$ & 505 (19.5) & $581(22.6)$ & $638(23.7)$ & $762(28.7)$ & $<.001$ \\
\hline Dyslipidemia & $898(8.5)$ & 199 (7.7) & $193(7.5)$ & $241(8.9)$ & $265(10.0)$ & 0.003 \\
\hline Atrial fibrillation & $763(7.3)$ & $161(6.2)$ & $164(6.4)$ & $196(7.3)$ & $242(9.1)$ & $<.001$ \\
\hline Ischemic stroke & $2,231(21.2)$ & $497(19.2)$ & $551(21.4)$ & $541(20.1)$ & $642(24.2)$ & $<.001$ \\
\hline TIA & $316(3.0)$ & $78(3.0)$ & $98(3.8)$ & $76(2.8)$ & $64(2.4)$ & 0.027 \\
\hline Myocardial infarction & $228(2.2)$ & $45(1.7)$ & $56(2.2)$ & $56(2.1)$ & $71(2.7)$ & 0.132 \\
\hline Angina & 411 (3.9) & $95(3.7)$ & $93(3.6)$ & $96(3.6)$ & $127(4.8)$ & 0.062 \\
\hline Venous thrombus & $39(0.4)$ & $11(0.4)$ & $9(0.4)$ & $8(0.3)$ & $11(0.4)$ & 0.856 \\
\hline Heart failure & $75(0.7)$ & $9(0.4)$ & $15(0.6)$ & $19(0.7)$ & $32(1.2)$ & 0.002 \\
\hline Smoking, n (\%) & $3348(31.8)$ & $968(37.4)$ & $833(32.4)$ & $817(30.3)$ & $730(27.5)$ & $<.001$ \\
\hline Drinking, n (\%) & $1502(14.3)$ & $446(17.2)$ & $368(14.3)$ & $365(13.4)$ & $323(12.2)$ & $<.001$ \\
\hline Baseline NIHSS, median (IQR) & $3.0(1.0-6.0)$ & $3.0(1.0-5.0)$ & $3.0(1.0-6.0)$ & $3.0(1.0-6.0)$ & $4.0(2.0-7.0)$ & $\begin{array}{l}< \\
0.001\end{array}$ \\
\hline $\begin{array}{l}\text { Time after event within } 24 \text { hours, } n \\
(\%)\end{array}$ & $7803(74.2)$ & $1933(74.6)$ & $1947(75.6)$ & $1967(72.9)$ & 1956 (73.7) & 0.149 \\
\hline $\begin{array}{l}\text { Baseline D-dimer, median (IQR), } \\
\mu \mathrm{g} / \mathrm{ml}\end{array}$ & $1.1(0.6-2.1)$ & $1.1(0.5-2.2)$ & $1.0(0.5-1.9)$ & $1.2(0.6-2.0)$ & $1.2(0.6-2.3)$ & $<.001$ \\
\hline $\begin{array}{l}\text { Baseline hsCRP, median (IQR), } \\
\mathrm{mg} / \mathrm{L}\end{array}$ & $1.8(0.8-4.8)$ & $1.1(0.6-2.5)$ & $1.3(0.7-3.1)$ & $2.0(1 .-4.7)$ & $4.3(1.7-12.8)$ & $\begin{array}{l}< \\
0.001\end{array}$ \\
\hline TOAST subtypes, n (\%) & & & & & & $<.001$ \\
\hline Large artery atherosclerosis & $2625(25.0)$ & $580(22.4)$ & $630(24.5)$ & $668(24.8)$ & $747(28.2)$ & \\
\hline Small artery occlusion & $2184(20.8)$ & $611(23.6)$ & $547(21.2)$ & $551(20.4)$ & 475 (17.9) & \\
\hline Cardioembolism & $685(6.5)$ & $155(6.0)$ & $165(6.4)$ & $163(6.0)$ & $202(7.6)$ & \\
\hline Other/undetermined & $116(1.1)$ & $27(1.0)$ & $26(1.0)$ & $28(1.0)$ & $35(1.3)$ & \\
\hline Undefined & $4908(46.7)$ & $1219(47.0)$ & $1208(46.9)$ & $1287(47.7)$ & $1194(45.0)$ & \\
\hline Intravenous thrombolysis, n (\%) & $1080(10.3)$ & $287(11.1)$ & $266(10.3)$ & $279(10.3)$ & $248(9.4)$ & 0.232 \\
\hline
\end{tabular}

$\mathrm{BMI}$ indicates body mass index (the weight in kilograms divided by the square of the height in meters); hsCRP, high-sensitive C-reactive protein; IQR, interquartile range; NIHSS, National Institutes of Health Stroke Scale; TIA, transient ischemic attack; and TOAST, Trial of Org 10172 in Acute Stroke Treatment.

*Quartiles of fibrinogen (mg/dl), Q1 < 315.0, Q2 = 315.0-377.9, Q3 = 378.0-451.5, Q4 > 451.5. 


\begin{tabular}{|c|c|c|c|c|c|c|}
\hline \multirow[t]{2}{*}{ Characteristics } & \multirow[t]{2}{*}{ All $(N=10518)$} & \multicolumn{4}{|c|}{ Quartiles of fibrinogen } & \multirow{2}{*}{$\begin{array}{l}P \\
\text { Value }\end{array}$} \\
\hline & & Q1 ( $N=2592)$ & Q2 (N = 2576) & Q3 (N = 2697) & Q4 $(\mathrm{N}=2653)^{*}$ & \\
\hline In-hospital antithrombotics, n (\%) & $10269(97.6)$ & $2545(98.2)$ & $2520(97.8)$ & $2627(97.4)$ & $2577(97.1)$ & 0.063 \\
\hline \multicolumn{7}{|c|}{ Complication during hospitalization, n (\%) } \\
\hline Pulmonary infection & $582(5.5)$ & $98(3.8)$ & $103(4.0)$ & $145(5.4)$ & $236(8.9)$ & $\begin{array}{l}< \\
0.001\end{array}$ \\
\hline Urinary infection & $156(1.5)$ & $22(0.9)$ & $28(1.1)$ & $45(1.7)$ & $61(2.3)$ & $\begin{array}{l}< \\
0.001\end{array}$ \\
\hline Deep vein thrombosis & $63(0.6)$ & $11(0.4)$ & $12(0.5)$ & $12(0.4)$ & $28(1.1)$ & 0.006 \\
\hline \multicolumn{7}{|c|}{$\begin{array}{l}\text { BMI indicates body mass index (the weight in kilograms divided by the square of the height in meters); hsCRP, high-sensitive C-reactive } \\
\text { protein; IQR, interquartile range; NIHSS, National Institutes of Health Stroke Scale; TIA, transient ischemic attack; and TOAST, Trial of Org } \\
10172 \text { in Acute Stroke Treatment. }\end{array}$} \\
\hline
\end{tabular}

\section{Fibrinogen and Poor Functional Outcome}

In total, $1446(13.9 \%)$ patients had a poor functional outcome at 90 days. In the quartile analyses, high fibrinogen levels were associated with an increased risk of poor functional outcome $(P$ for trend $<0.001)$ at 90 days $($ Table 2$)$. 
Table 2

Clinical Outcomes

\begin{tabular}{|c|c|c|c|c|c|c|}
\hline \multirow[t]{2}{*}{ Outcome } & \multirow[t]{2}{*}{ Groups* } & \multicolumn{3}{|c|}{ 90-day follow-up } & \multicolumn{2}{|c|}{ 1-year follow-up } \\
\hline & & $\mathbf{n}$ & Events, n (\%) & $P$ for trend & Events, n (\%) & $P$ for trend \\
\hline \multirow[t]{5}{*}{ mRS score of $\geq 3$} & & & & $<0.001$ & & $<0.001$ \\
\hline & Q1 & 2560 & $263(10.27)$ & & $231(9.15)$ & \\
\hline & Q2 & 2558 & 295 (11.53) & & $283(11.20)$ & \\
\hline & Q3 & 2669 & $378(14.16)$ & & $366(13.90)$ & \\
\hline & Q4 & 2601 & $510(19.61)$ & & 491 (19.13) & \\
\hline \multirow[t]{5}{*}{ Stroke } & & & & 0.014 & & 0.002 \\
\hline & Q1 & 2592 & $132(5.09)$ & & $212(8.18)$ & \\
\hline & Q2 & 2576 & $154(5.98)$ & & $261(10.13)$ & \\
\hline & Q3 & 2697 & $185(6.86)$ & & $284(10.53)$ & \\
\hline & Q4 & 2653 & $186(7.01)$ & & $285(10.74)$ & \\
\hline \multirow[t]{5}{*}{ Ischemic stroke } & & & & 0.002 & & 0.002 \\
\hline & Q1 & 2592 & $124(4.78)$ & & $195(7.52)$ & \\
\hline & Q2 & 2576 & $145(5.63)$ & & $239(9.28)$ & \\
\hline & Q3 & 2697 & $168(6.23)$ & & $256(9.49)$ & \\
\hline & Q4 & 2653 & $179(6.75)$ & & $267(10.06)$ & \\
\hline \multirow[t]{5}{*}{ Composite eventsł } & & & & 0.001 & & 0.001 \\
\hline & Q1 & 2592 & $136(5.25)$ & & $225(8.68)$ & \\
\hline & Q2 & 2576 & $160(6.21)$ & & $274(10.64)$ & \\
\hline & Q3 & 2697 & $190(7.04)$ & & $298(11.05)$ & \\
\hline & Q4 & 2653 & $194(7.31)$ & & $302(11.38)$ & \\
\hline \multicolumn{7}{|c|}{ *Quartiles of fibrinogen (mg/dl), Q1 <315.0, Q2 = 315.0-377.9, Q3 = 378.0-451.5, Q4 > 451.5. } \\
\hline
\end{tabular}

After adjustment for age, sex, histories of hypertension, diabetes mellitus, dyslipidemia, atrial fibrillation, ischemic stroke, TIA, and heart failure, baseline National Institutes of Health Stroke Scale score (NIHSS), smoking, drinking, stroke subtypes, D-dimer, hsCRP, and complications during hospitalization, fibrinogen levels in Q3 (378.0-451.5 mg/dl) and Q4 (> $451.5 \mathrm{mg} / \mathrm{dl}$ ) were associated with poor functional outcome (adjusted odds ratio [OR], 1.28; $95 \% \mathrm{Cl}, 1.06-1.55$ and adjusted OR, 1.35; 95\% Cl, 1.12-1.64) compared with a fibrinogen level in Q1 (<315.0 mg/dl) (Table 3). High fibrinogen levels also independently predicted poor functional outcome during the 1-year follow-up. Similar results were observed when fibrinogen was assessed as a continuous variable (Table 3). 
Table 3

Odd ratio/hazard ratio of outcomes according to fibrinogen quartile categories

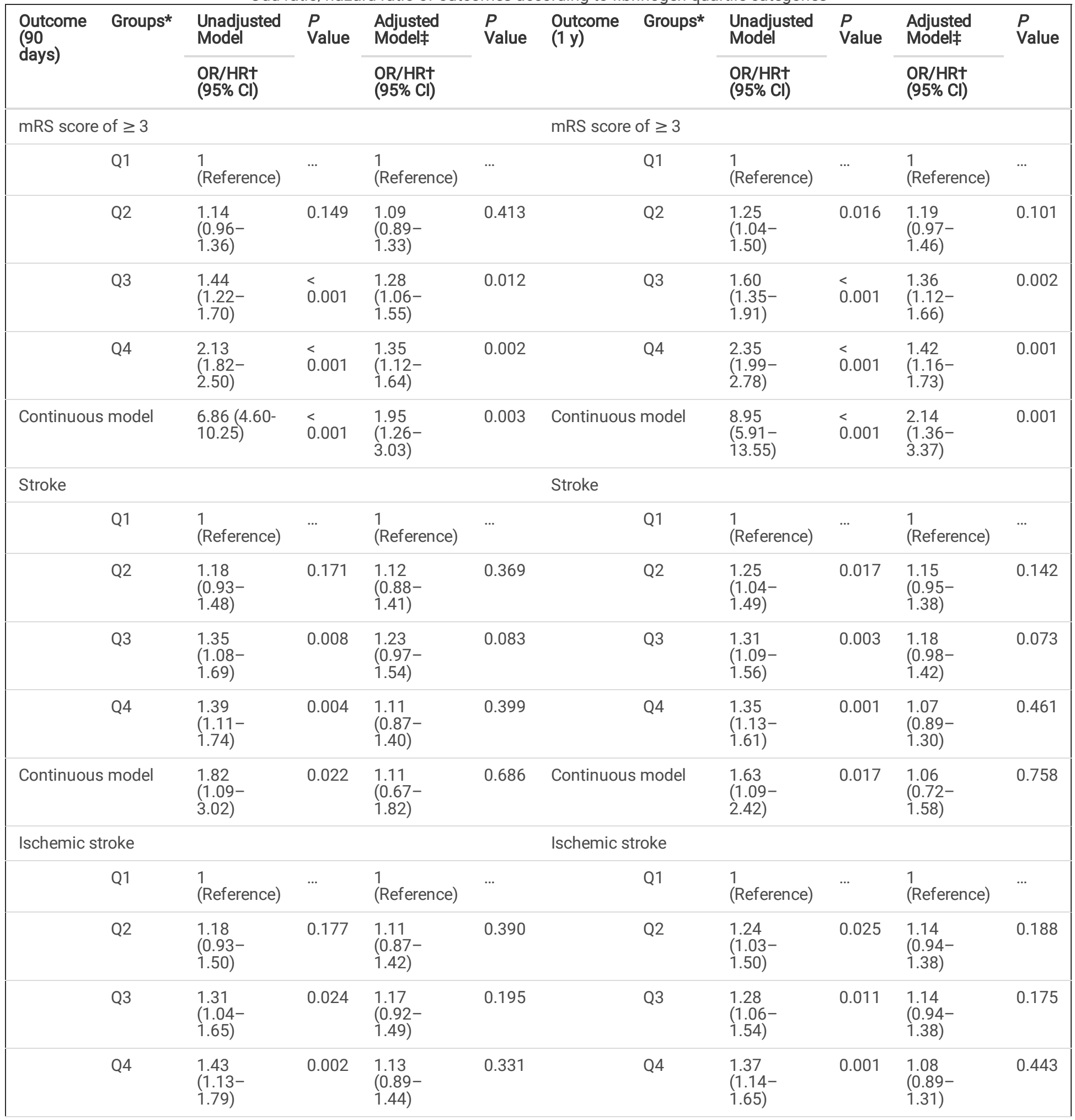

$\mathrm{Cl}$ indicates confidence interval; $\mathrm{HR}$, hazard ratio; and $\mathrm{OR}$, odd ratio.

* Quartiles of fibrinogen (mg/dl), Q1 < 315.0, Q2 = 315.0-377.9, Q3 = 378.0-451.5, Q4 > 451.5.

TOR for poor functional outcome, while HR for stroke recurrence, ischemic stroke recurrence, and composite events.

$\ddagger$ Adjusted for age, sex, histories of hypertension, diabetes mellitus, dyslipidemia, atrial fibrillation, ischemic stroke, transient ischemic attack, and heart failure, baseline National Institutes of Health Stroke Scale score, smoking, drinking, stroke subtypes, baseline D-dimer, baseline hsCRP, pulmonary infection, urinary infection, and deep vein thrombosis during hospitalization

§Composite events were composed of ischemic stroke, hemorrhagic stroke, myocardial infarction, and vascular death 


\begin{tabular}{|c|c|c|c|c|c|c|c|c|c|c|c|}
\hline \multirow{2}{*}{$\begin{array}{l}\text { Outcome } \\
\text { (90 } \\
\text { days) }\end{array}$} & \multirow[t]{2}{*}{ Groups* } & $\begin{array}{l}\text { Unadjusted } \\
\text { Model }\end{array}$ & \multirow[t]{2}{*}{$\begin{array}{l}P \\
\text { Value }\end{array}$} & \multirow{2}{*}{$\begin{array}{l}\begin{array}{l}\text { Adjusted } \\
\text { Modelf }\end{array} \\
\text { OR/HRt } \\
\text { (95\% Cl) }\end{array}$} & \multirow[t]{2}{*}{$\begin{array}{l}P \\
\text { Value }\end{array}$} & \multirow[t]{2}{*}{$\begin{array}{l}\text { Outcome } \\
(1 \mathrm{y})\end{array}$} & \multirow[t]{2}{*}{ Groups* } & \multirow{2}{*}{$\begin{array}{l}\text { Unadjusted } \\
\text { Model }\end{array}$} & \multirow[t]{2}{*}{$\begin{array}{l}P \\
\text { Value }\end{array}$} & $\begin{array}{l}\text { Adjusted } \\
\text { Model } \neq\end{array}$ & \multirow[t]{2}{*}{$\begin{array}{l}P \\
\text { Value }\end{array}$} \\
\hline & & $\begin{array}{l}\text { OR/HRT } \\
\text { (95\% Cl) }\end{array}$ & & & & & & & & $\begin{array}{l}\text { OR/HRt } \\
\text { (95\% Cl) }\end{array}$ & \\
\hline \multicolumn{2}{|c|}{ Continuous model } & $\begin{array}{l}1.88 \\
(1.11- \\
3.19)\end{array}$ & 0.019 & $\begin{array}{l}1.13 \\
(0.68- \\
1.90)\end{array}$ & 0.637 & \multicolumn{2}{|c|}{ Continuous model } & $\begin{array}{l}1.65 \\
(1.09- \\
2.51)\end{array}$ & 0.018 & $\begin{array}{l}1.05 \\
(0.70- \\
1.58)\end{array}$ & 0.812 \\
\hline \multicolumn{6}{|c|}{ Composite events§ } & \multicolumn{6}{|c|}{ Composite events§ } \\
\hline & Q1 & $\begin{array}{l}1 \\
\text { (Reference) }\end{array}$ & $\ldots$ & $\begin{array}{l}1 \\
\text { (Reference) }\end{array}$ & $\ldots$ & & Q1 & $\begin{array}{l}1 \\
\text { (Reference) }\end{array}$ & $\ldots$ & $\begin{array}{l}1 \\
\text { (Reference) }\end{array}$ & $\ldots$ \\
\hline & Q2 & $\begin{array}{l}1.19 \\
(0.94- \\
1.49)\end{array}$ & 0.171 & $\begin{array}{l}1.13 \\
(0.89- \\
1.42)\end{array}$ & 0.323 & & Q2 & $\begin{array}{l}1.23 \\
(1.03- \\
1.47)\end{array}$ & 0.020 & $\begin{array}{l}1.14 \\
(0.95- \\
1.36)\end{array}$ & 0.163 \\
\hline & Q3 & $\begin{array}{l}1.35 \\
(1.08- \\
1.68)\end{array}$ & 0.008 & $\begin{array}{l}1.22 \\
(0.97- \\
1.53)\end{array}$ & 0.086 & & Q3 & $\begin{array}{l}1.29 \\
(1.09- \\
1.54)\end{array}$ & 0.004 & $\begin{array}{l}1.16 \\
(0.98- \\
1.39)\end{array}$ & 0.093 \\
\hline & Q4 & $\begin{array}{l}1.41 \\
(1.13- \\
1.75)\end{array}$ & 0.002 & $\begin{array}{l}1.11 \\
(0.88- \\
1.40)\end{array}$ & 0.388 & & Q4 & $\begin{array}{l}1.35 \\
(1.13- \\
1.60)\end{array}$ & 0.001 & $\begin{array}{l}1.05 \\
(0.87- \\
1.26)\end{array}$ & 0.616 \\
\hline \multicolumn{2}{|c|}{ Continuous model } & $\begin{array}{l}1.90 \\
(1.15- \\
3.13)\end{array}$ & 0.013 & $\begin{array}{l}1.12 \\
(0.68- \\
1.82)\end{array}$ & 0.662 & \multicolumn{2}{|c|}{ Continuous model } & $\begin{array}{l}1.66 \\
(1.13- \\
2.45)\end{array}$ & 0.011 & $\begin{array}{l}1.03 \\
(0.71- \\
1.51)\end{array}$ & 0.871 \\
\hline \multicolumn{12}{|c|}{$\mathrm{Cl}$ indicates confidence interval; HR, hazard ratio; and OR, odd ratio. } \\
\hline \multicolumn{12}{|c|}{ * Quartiles of fibrinogen (mg/dl), Q1 <315.0, Q2 = 315.0-377.9, Q3 = 378.0-451.5, Q4 > 451.5. } \\
\hline \multicolumn{12}{|c|}{ TOR for poor functional outcome, while HR for stroke recurrence, ischemic stroke recurrence, and composite events. } \\
\hline \multicolumn{12}{|c|}{$\begin{array}{l}\text { ¥Adjusted for age, sex, histories of hypertension, diabetes mellitus, dyslipidemia, atrial fibrillation, ischemic stroke, transient ischemic attack, } \\
\text { and heart failure, baseline National Institutes of Health Stroke Scale score, smoking, drinking, stroke subtypes, baseline D-dimer, baseline } \\
\text { hsCRP, pulmonary infection, urinary infection, and deep vein thrombosis during hospitalization }\end{array}$} \\
\hline
\end{tabular}

Using a regression model with a restricted cubic spline, we observed an association between high fibrinogen levels and an increased risk of poor functional outcome at 90 days and 1 year (Fig. 2).

\section{Fibrinogen and Stroke Recurrence}

There were 657 (6.3\%) patients with stroke recurrence within 90 days. In the quartile analyses, high fibrinogen levels were significantly associated with an increased risk of 90-day stroke recurrence, ischemic stroke recurrence, and composite vascular events $(P$ for trend $=0.014,=$ 0.002 , and $=0.001$, respectively) (Table 2 ). After adjustment for confounding risk factors, these associations were no longer significant (Table 3 ). Furthermore, fibrinogen levels were not associated with a new vascular disease during the 1-year follow-up. Similar results were observed when fibrinogen was assessed as a continuous variable (Table 3).

\section{Discussions}

In this prospective hospital-based nationwide stroke registry in China, we found that high fibrinogen levels were associated with increased risks of short-term and long-term poor functional outcome, but not stroke recurrence, ischemic stroke recurrence, and composite vascular events in patients with acute ischemic stroke or TIA.

Although previous studies confirmed that a high fibrinogen level was associated with first-ever cardiovascular disease [5, 6], the association between fibrinogen and ischemic stroke is contradictory. A large meta-analysis involving 154211 participants proved that moderately strong associations were found between plasma fibrinogen and the risk of first stroke in healthy middle-aged adults [26]. However, subsequent studies investigating the association between fibrinogen and initial ischemic stroke showed inconsistent results [7, 27-29]. In contrast, only a few studies indicated that fibrinogen level was associated with stroke recurrence in recent TIA or minor ischemic stroke [12, 30] A preliminary study showed that fibrinogen combined with tissue-type plasminogen activator and von Willebrand factor was associated with coronary events, but not stroke recurrence among patients with recent TIA or ischemic stroke [31]. In addition, previous studies have indicated that the association 
between fibrinogen and a new vascular event was no longer significant after adjustment for confounding risk factors in patients with acute stroke $[10,11]$. On the contrary, the association between fibrinogen and poor functional outcome is less established. It was previously suggested that fibrinogen was associated with poor functional outcome after adjusted simple risk factors, but further adjustment for potential factors eliminated this association [32]. Previous studies suggested that patients with lower initial fibrinogen levels had good functional outcome after acute stroke, indicating that the independent association between fibrinogen levels and functional outcomes need to be verified using a larger acute stroke dataset [16]. In the present study, the associations of fibrinogen with poor functional outcome and stroke recurrence were assessed base on a large-scale stroke registry study in China. Furthermore, D-dimer, hsCRP, and complications during hospitalization were considered in addition to the baseline NIHSS score and stroke subtype according to the Trial of Org 10172 in Acute Stroke Treatment.

In our analysis, high fibrinogen levels were associated with an increased risk of poor functional outcome. This association was independent of the stroke severity, stroke subtype, complications, D-dimer, and hsCRP. Our findings indicate that this association might depend on other potential mechanisms of fibrinogen. One possible explanation is that high fibrinogen level may affect the structure of the fibrin clot. Previous studies have suggested that high fibrinogen levels might be related to the formation of more stable fibrin clots, which determine the efficacy of arterial recanalization [33]. Another potential explanation is that high fibrinogen levels cause high blood viscosity, which could potentially compromise the microvascular blood flow in marginally perfused brain areas [16]. An additional explanation is that fibrinogen plays a critical role in interfering with tissue repair [3].Blood-brain barrier permeability increases after ischemia and reperfusion [34], and fibrinogen enters the brain tissue, thus participating in acute tissue necrosis and causing secondary tissue damage [35, 36]. Based on our findings, high fibrinogen levels independently predict poor functional outcome, which suggest that fibrinogen might be a targeted therapeutic after acute ischemic stroke or TIA.

Consistent with previous studies, we observed no association between fibrinogen and a new vascular event in the multivariate model [11]. Potential explanation might be that fibrinogen levels were associated with other risk factors. Although fibrinogen is the most common hemostatic factor, its role in the development of atherosclerosis and vascular disease extends to a key proinflammatory player [3]. The Canakinumab Antiinflammatory Thrombosis Outcome Study showed that antiinflammatory therapy led to the reduction in hsCRP and fibrinogen, indicating that fibrinogen had potentially plays dual roles as both an acute-phase reactant and a mediator of coagulation [37]. Previous studies proved that there was a strong association between fibrinogen and hsCRP [10]. In addition, it has been suggested that hsCRP was more related to the risk of new cardiovascular events after acute ischemic stroke than fibrinogen [11]. Therefore, our findings suggest that fibrinogen might be involved in stroke recurrence through other critical risk factors.

Our study has several limitations. First, our study only included the D-dimer and hsCRP levels in addition to the fibrinogen levels, while other related coagulation or inflammatory factors may also be associated with stroke outcomes. Future studies focusing on the coagulation or inflammatory pathway could help to reveal the molecular mechanism underlying stroke outcomes. Second, this study obtained one-point fibrinogen measurements. Since fibrinogen levels persistently increase from the acute phase to the stable phase in patients after stroke [8,9], dynamic change might be necessary to confirm its predictive value. Third, 4648 (30.6\%) of the 15166 patients did not provide blood samples and were excluded because their fibrinogen levels were not measured. Although the baseline characteristics of the patients included and those excluded were well balanced, some deviation in the analysis of the associations between the fibrinogen levels and outcomes may exist. Finally, all enrolled patients were Chinese adults with acute ischemic stroke or TIA, and these results may not be generalizable to patients of other ethnicities.

\section{Conclusions}

In conclusion, our study show that high fibrinogen levels were associated with poor functional outcome, but not with stroke recurrence, ischemic stroke recurrence, or composite vascular events.

\section{Abbreviations}

BMI: Body mass index (the weight in kilograms divided by the square of the height in meters); Cl: Confidence interval; CNSRヌ: Third China National Stroke Registry; HR: Hazard ratio; hsCRP: High-sensitive C-reactive protein; IQR: Interquartile range; NIHSS: National Institutes of Health Stroke Scale; OR: Odd ratio; TIA: Transient ischemic attack; TOAST: Trial of Org 10172 in Acute Stroke Treatment.

\section{Declarations}

\section{Acknowledgements}

We are grateful to the study participants and the staff at all participating hospitals for their support with patient recruitment.

\section{Authors' contributions}


YW had full access to all of the data in the study and takes responsibility for the integrity of the data and the accuracy of the data analysis. Study concept and design: YW, HH, WL, QZ and XM. Drafting of the manuscript: YW and HH. Statistical analysis: XX, YP and HL.

\section{Funding}

This study was supported by grants from Beijing Municipal Science \& Technology Commission (D171100003017002, Z181100001818001), the Ministry of Science and Technology of the People's Republic of China (2018YFC1312903), and National Natural Science Foundation of China (81870905).

\section{Availability of data and materials}

The corresponding author takes full responsibility for the data, the analyses and interpretation, and the conduct of the research; that he has full access to all of the data.

\section{Ethics approval and consent to participate}

The study protocol was approved by the Central Institutional Review Board at the Beijing TianTan Hospital. All participants or their legal proxies provided written informed consent.

\section{Consent for publication}

Not applicable.

\section{Competing interests}

None declared.

\section{References}

1. Du W, Zhao X, Wang Y, Pan Y, Liu G, Wang A, Ji R, Liu L, Gu H, Dong K, Wang P, Wang Y, China National Stroke Registry (CNSR) investigators. Gastrointestinal bleeding during acute ischaemic stroke hospitalisation increases the risk of stroke recurrence. Stroke Vasc Neurol 2020;5(2):116-120.

2. Kleindorfer D, Panagos P, Pancioli A, Khoury J, Kissela B, Woo D, Schneider A, Alwell K, Jauch E, Miller R, Moomaw C, Shukla R, Broderick JP. Incidence and short-term prognosis of transient ischemic attack in a population-based study. Stroke 2005;36(4):720-3.

3. Davalos D, Akassoglou K. Fibrinogen as a key regulator of inflammation in disease. Semin Immunopathol 2012;34(1):43-62.

4. Koenig W. Fibrin(ogen) in cardiovascular disease: an update. Thromb Haemost 2003;89(4):601-9.

5. Tzoulaki I, Murray GD, Lee AJ, Rumley A, Lowe GD, Fowkes FG. Relative value of inflammatory, hemostatic, and rheological factors for incident myocardial infarction and stroke: the Edinburgh Artery Study. Circulation 2007;115(16):2119-27.

6. Smith A, Patterson C, Yarnell J, Rumley A, Ben-Shlomo Y, Lowe G. Which hemostatic markers add to the predictive value of conventional risk factors for coronary heart disease and ischemic stroke? The Caerphilly Study. Circulation 2005;112(20):3080-7.

7. Chuang SY, Bai CH, Chen WH, Lien LM, Pan WH. Fibrinogen independently predicts the development of ischemic stroke in a Taiwanese population: CVDFACTS study. Stroke 2009;40(5):1578-84.

8. Shenhar-Tsarfaty S, Ben Assayag E, Bova I, Shopin L, Cohen M, Berliner S, Shapira I, Bornstein NM. Persistent hyperfibrinogenemia in acute ischemic stroke / transient ischemic attack (TIA). Thromb Haemost 2008;99(1):169-73.

9. Marquardt L, Ruf A, Mansmann U, Winter R, Buggle F, Kallenberg K, Grau AJ. Inflammatory response after acute ischemic stroke. J Neurol Sci 2005;236(1-2):65-71.

10. Di Napoli M, Papa F, Bocola V. Prognostic influence of increased C-reactive protein and fibrinogen levels in ischemic stroke. Stroke 2001;32(1):133-8.

11. Di Napoli M, Papa F. Inflammation, hemostatic markers, and antithrombotic agents in relation to long-term risk of new cardiovascular events in first-ever ischemic stroke patients. Stroke 2002;33(7):1763-71.

12. Williams SR, Hsu FC, Keene KL, Chen WM, Nelson S, Southerland AM, Madden EB, Coull B, Gogarten SM, Furie KL, Dzhivhuho G, Rowles JL, Mehndiratta P, Malik R, Dupuis J, Lin H, Seshadri S, Rich SS, Sale MM, Worrall BB. Shared genetic susceptibility of vascular-related biomarkers with ischemic and recurrent stroke. Neurology 2016;86(4):351-9.

13. Swarowska M, Polczak A, Pera J, Klimkowicz-Mrowiec A, Slowik A, Dziedzic T. Hyperfibrinogenemia predicts long-term risk of death after ischemic stroke. J Thromb Thrombolysis 2014;38(4):517-21. 
14. Markaki I, Franzén I, Talani C, Loizou L, Kostulas N. Long-term survival of ischemic cerebrovascular disease in the acute inflammatory stroke study, a hospital-based cohort described by TOAST and ASCO. Cerebrovasc Dis 2013;35(3):213-9.

15. Turaj W, Słowik A, Dziedzic T, Pułyk R, Adamski M, Strojny J, Szczudlik A. Increased plasma fibrinogen predicts one-year mortality in patients with acute ischemic stroke. J Neurol Sci 2006;246(1-2):13-9.

16. del Zoppo GJ, Levy DE, Wasiewski WW, Pancioli AM, Demchuk AM, Trammel J, Demaerschalk BM, Kaste M, Albers GW, Ringelstein EB. Hyperfibrinogenemia and functional outcome from acute ischemic stroke. Stroke 2009;40(5):1687-91.

17. Lee WJ, Jung KH, Ryu YJ, Lee KJ, Lee ST, Chu K, Lee SK, Roh JK. Acute Symptomatic Basilar Artery Stenosis: MR Imaging Predictors of Early Neurologic Deterioration and Long-term Outcomes. Radiology 2016;280(1):193-201.

18. Sattar N, Murray HM, Welsh P, Blauw GJ, Buckley BM, Cobbe S, de Craen AJ, Lowe GD, Jukema JW, Macfarlane PW, Murphy MB, Stott DJ, Westendorp RG, Shepherd J, Ford I, Packard CJ. Are markers of inflammation more strongly associated with risk for fatal than for nonfatal vascular events. PLoS Med 2009;6(6):e1000099.

19. Wang Y, Jing J, Meng X, Pan Y, Wang Y, Zhao X, Lin J, Li W, Jiang Y, Li Z, Zhang X, Yang X, Ji R, Wang C, Wang Z, Han X, Wu S, Jia Z, Chen Y, $\mathrm{Li} \mathrm{H}$. The Third China National Stroke Registry (CNSR-III) for patients with acute ischaemic stroke or transient ischaemic attack: design, rationale and baseline patient characteristics. Stroke Vasc Neurol 2019;4(3):158-164.

20. Stroke-1989. Recommendations on stroke prevention, diagnosis, and therapy. Report of the WHO Task Force on Stroke and other Cerebrovascular Disorders. Stroke 1989;20(10):1407-31.

21. Whitton CM, Sands D, Hubbard AR, Gaffney PJ. A collaborative study to establish the 2nd International Standard for Fibrinogen, Plasma. Thromb Haemost 2000;84(2):258-62.

22. Mora S, Rifai N, Buring JE, Ridker PM. Additive value of immunoassay-measured fibrinogen and high-sensitivity C-reactive protein levels for predicting incident cardiovascular events. Circulation 2006;114(5):381-7.

23. Folsom AR, Gottesman RF, Appiah D, Shahar E, Mosley TH. Plasma d-Dimer and Incident Ischemic Stroke and Coronary Heart Disease: The Atherosclerosis Risk in Communities Study. Stroke 2016;47(1):18-23.

24. Jia Q, Zhao X, Wang C, Wang Y, Yan Y, Li H, Zhong L, Liu L, Zheng H, Zhou Y, Wang Y. Diabetes and poor outcomes within 6 months after acute ischemic stroke: the China National Stroke Registry. Stroke 2011;42(10):2758-62.

25. Jing J, Pan Y, Zhao X, Zheng H, Jia Q, Mi D, Chen W, Li H, Liu L, Wang C, He Y, Wang D, Wang Y, Wang Y, investigators for ACROSS-China. Insulin Resistance and Prognosis of Nondiabetic Patients With Ischemic Stroke: The ACROSS-China Study (Abnormal Glucose Regulation in Patients With Acute Stroke Across China). Stroke 2017;48(4):887-893.

26. Danesh J, Lewington S, Thompson SG, Lowe GD, Collins R, Kostis JB, Wilson AC, Folsom AR, Wu K, Benderly M, Goldbourt U, Willeit J, Kiechl S, Yarnell JW, Sweetnam PM, Elwood PC, Cushman M, Psaty BM, Tracy RP, Tybjaerg-Hansen A, Haverkate F, de Maat MP, Fowkes FG, Lee AJ, Smith FB, Salomaa V, Harald K, Rasi R, Vahtera E, Jousilahti P, Pekkanen J, D'Agostino R, Kannel WB, Wilson PW, Tofler G, Arocha-Piñango CL, Rodriguez-Larralde A, Nagy E, Mijares M, Espinosa R, Rodriquez-Roa E, Ryder E, Diez-Ewald MP, Campos G, Fernandez V, Torres E, Marchioli R, Valagussa F, Rosengren A, Wilhelmsen L, Lappas G, Eriksson H, Cremer P, Nagel D, Curb JD, Rodriguez B, Yano K, Salonen JT, Nyyssönen K, Tuomainen TP, Hedblad B, Lind P, Loewel H, Koenig W, Meade TW, Cooper JA, De Stavola B, Knottenbelt C, Miller GJ, Cooper JA, Bauer KA, Rosenberg RD, Sato S, Kitamura A, Naito Y, Palosuo T, Ducimetiere P, Amouyel P, Arveiler D, Evans AE, Ferrieres J, Juhan-Vague I, Bingham A, Schulte H, Assmann G, Cantin B, Lamarche B, Després JP, Dagenais GR, Tunstall-Pedoe H, Woodward M, Ben-Shlomo Y, Davey Smith G, Palmieri V, Yeh JL, Rudnicka A, Ridker P, Rodeghiero F, Tosetto A, Shepherd J, Ford I, Robertson M, Brunner E, Shipley M, Feskens EJ, Kromhout D, Dickinson A, Ireland B, Juzwishin K, Kaptoge S, Lewington S, Memon A, Sarwar N, Walker M, Wheeler J, White I, Wood A. Plasma fibrinogen level and the risk of major cardiovascular diseases and nonvascular mortality: an individual participant meta-analysis. JAMA 2005;294(14):1799-809.

27. Patterson CC, Smith AE, Yarnell JW, Rumley A, Ben-Shlomo Y, Lowe GD. The associations of interleukin-6 (IL-6) and downstream inflammatory markers with risk of cardiovascular disease: the Caerphilly Study. Atherosclerosis 2010;209(2):551-7.

28. Appiah D, Schreiner PJ, MacLehose RF, Folsom AR. Association of Plasma y' Fibrinogen With Incident Cardiovascular Disease: The Atherosclerosis Risk in Communities (ARIC) Study. Arterioscler Thromb Vasc Biol 2015;35(12):2700-6.

29. Prugger C, Luc G, Haas B, Morange PE, Ferrieres J, Amouyel P, Kee F, Ducimetiere P, Empana JP, PRIME Study Group. Multiple biomarkers for the prediction of ischemic stroke: the PRIME study. Arterioscler Thromb Vasc Biol 2013;33(3):659-66.

30. Rothwell PM, Howard SC, Power DA, Gutnikov SA, Algra A, van Gijn J, Clark TG, Murphy MF, Warlow CP. Fibrinogen concentration and risk of ischemic stroke and acute coronary events in 5113 patients with transient ischemic attack and minor ischemic stroke. Stroke 2004;35(10):2300-5.

31. Pedersen A, Redfors P, Lundberg L, Gils A, Declerck PJ, Nilsson S, Jood K, Jern C. Haemostatic biomarkers are associated with long-term recurrent vascular events after ischaemic stroke. Thromb Haemost 2016;116(3):537-43.

32. Whiteley W, Jackson C, Lewis S, Lowe G, Rumley A, Sandercock P, Wardlaw J, Dennis M, Sudlow C. Inflammatory markers and poor outcome after stroke: a prospective cohort study and systematic review of interleukin-6. PLoS Med 2009;6(9):e1000145.

Page 11/13 
33. González-Conejero R, Fernández-Cadenas I, Iniesta JA, Marti-Fabregas J, Obach V, Alvarez-Sabín J, Vicente V, Corral J, Montaner J, Proyecto Ictus Research Group. Role of fibrinogen levels and factor XIII V34L polymorphism in thrombolytic therapy in stroke patients. Stroke 2006;37(9):2288-93.

34. Kastrup A, Gröschel K, Ringer TM, Redecker C, Cordesmeyer R, Witte OW, Terborg C. Early disruption of the blood-brain barrier after thrombolytic therapy predicts hemorrhage in patients with acute stroke. Stroke 2008;39(8):2385-7.

35. Baeten KM, Akassoglou K. Extracellular matrix and matrix receptors in blood-brain barrier formation and stroke. Dev Neurobiol 2011;71(11):1018-39.

36. Adhami F, Liao G, Morozov YM, Schloemer A, Schmithorst VJ, Lorenz JN, Dunn RS, Vorhees CV, Wills-Karp M, Degen JL, Davis RJ, Mizushima N, Rakic P, Dardzinski BJ, Holland SK, Sharp FR, Kuan CY. Cerebral ischemia-hypoxia induces intravascular coagulation and autophagy. Am J Pathol 2006;169(2):566-83.

37. Ridker PM, Howard CP, Walter V, Everett B, Libby P, Hensen J, Thuren T, CANTOS Pilot Investigative Group. Effects of interleukin-1 $\beta$ inhibition with canakinumab on hemoglobin A1c, lipids, C-reactive protein, interleukin-6, and fibrinogen: a phase Ilb randomized, placebo-controlled trial. Circulation 2012;126(23):2739-48.

Figures

$$
\begin{aligned}
& 15166 \text { patients from } 201 \text { hospitals with } \\
& \text { acute ischemic stroke or TIA in CNSRIII } \\
& \qquad \begin{array}{l}
4648 \text { patients without } \\
\text { blood samples }
\end{array} \\
& \hline
\end{aligned}
$$

10518 patients from 171 hospitals were determined for fibrinogen

Follow up to 90 days:

1446 patients with mRS3-6 (130 lost to follow up) 657 patients with stroke recurrence 616 patients with ischemic stroke recurrence 680 patients with composite vascular events

Follow up to 1 year:
1371 patients with mRS3-6 (267 lost to follow up)
1042 patients with stroke recurrence
957 patients with ischemic stroke recurrence
1099 patients with composite vascular events

Figure 1

Flow chart for the cohort selection process. CNSR囚, the Third China National Stroke Registry; mRS, modified Rankin Scale. 

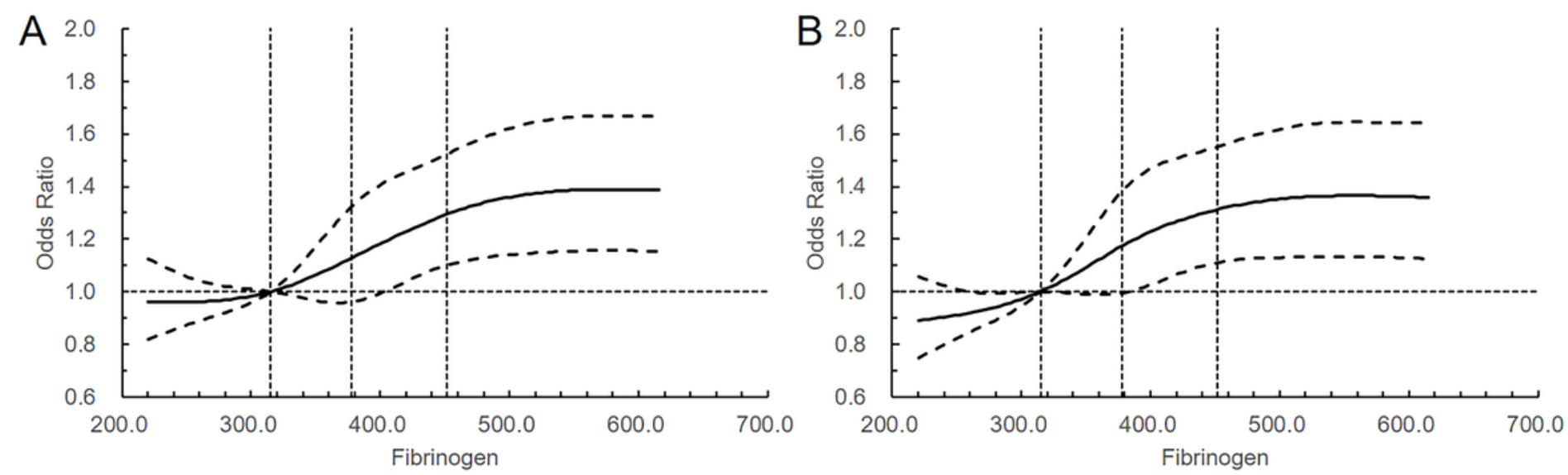

\section{Figure 2}

Adjusted ORs of poor functional outcome in patients stratified according to fibrinogen levels. (A) at 90 days and (B) at 1 year. The solid line indicates adjusted ORs and the dashed lines indicate the $95 \% \mathrm{Cl}$ bands. The reference is the first quartile of fibrinogen levels $(315.0 \mathrm{mg} / \mathrm{dl})$. The vertical dashed lines indicate the first, second, and third quartiles of fibrinogen levels. The data from the lowest $5 \%$ and highest $5 \%$ of patients are not shown. 